\title{
Kinetics of trans-10, cis-12-conjugated linoleic acid transfer to plasma and milk following an abomasal bolus in lactating dairy cows
}

\author{
Natalie L. Urrutia ${ }^{1}$, Monica Toledo ${ }^{2}$, Michel Baldin ${ }^{2}$, Jennifer L. Ford ${ }^{3}$, Michael H. Green ${ }^{3}$ and \\ Kevin J. Harvatine ${ }^{2 *}$ \\ ${ }^{1}$ Instituto de Investigaciones Agropecuarias (INIA) Remehue, Osorno 5290000, Chile \\ ${ }^{2}$ Department of Animal Science, The Pennsylvania State University, University Park, Pennsylvania, PA 16802, USA \\ ${ }^{3}$ Department of Nutritional Sciences, The Pennsylvania State University, University Park, Pennsylvania, PA 16802, USA
}

(Submitted 10 October 2017 - Final revision received 3 May 2018 - Accepted 5 May 2018)

\section{Abstract}

Trans-10, cis-12-conjugated linoleic acid (CLA) is a potent bioactive fatty acids (FA) that causes milk fat depression in lactating animals. FA are transferred to milk directly through chylomicrons and indirectly by recycling through other tissues. The objective of this study was to characterise the kinetics of trans-10, cis-12 CLA transfer to plasma and milk after a single bolus infusion. Five multiparous mid-lactation cows received a single abomasal bolus infusion of an enriched CLA mixture providing $15 \mathrm{~g}$ of trans-10, cis-12 CLA and 15 g of cis-9, trans-11 CLA over a 30-min period. Plasma concentration of trans-10, cis-12 and cis-9, trans-11 CLA peaked $2 \mathrm{~h}$ post-bolus, reaching $0 \cdot 29$ and $0.38 \%$ of total plasma FA, respectively, and returned to pre-bolus values at $72 \mathrm{~h}$ post-infusion. Milk trans-10, cis-12 CLA yield and concentration peaked $14 \mathrm{~h}$ post-bolus $(0.25 \mathrm{~g} / \mathrm{h})$ and was not detectable in milk after $86 \mathrm{~h}$. Total apparent transfer of trans-10, cis-12 CLA to milk was $41 \%$, with $73 \%$ transferred to milk through the direct pool (chylomicrons) and the remaining $27 \%$ transferred through the indirect pool (tissue recycling). Compartmental modelling revealed the existence of a transient unavailable pool of trans-10, cis-12 CLA in extravascular tissues represented primarily by the mammary gland, which slowly exchanges with an available pool for secretion in milk fat and transfer to milk. In conclusion, trans-10, cis-12 CLA is predominantly transferred to milk through the direct pathway; however, how this CLA isomer is processed within the mammary gland requires further investigation.

Key words: Conjugated linoleic acids: Fatty acids: Compartmental modelling: Lipid trafficking: Milk fat

Conjugated linoleic acids (CLA) are a group of geometrical and positional fatty acids (FA) isomers that are naturally found in ruminant meat and milk products and have shown to possess bioactive properties in diverse animal models ${ }^{(1)}$. Extensive research on the synthesis of cis-9, trans-11 and trans-10, cis-12 CLA in the rumen and their effect on metabolism has been conducted and are of special interest to dairy science ${ }^{(2)}$. Briefly, cis-9, trans-11 CLA is the main CLA isomer found in milk, and it originates directly from ruminal biohydrogenation (BH) of dietary linolenic and linoleic acid (LA), and from endogenous synthesis from trans-11 C18:1 by stearoyl-CoA desaturase (SCD1) in the mammary gland ${ }^{(3)}$. Trans-10, cis-12 CLA, if present, is found at very low concentrations in milk and originates exclusively from altered ruminal $\mathrm{BH}$ of dietary FA when lowfibre/high-starch diets or high unsaturated FA diets are fed ${ }^{(4)}$. Trans-10, cis-12 CLA reduces milk fat synthesis up to $50 \%$ through down-regulation of lipogenic capacity, key lipogenic enzymes and factors in mammary tissue, and is the causative factor of BH-induced milk fat depression (MFD) ${ }^{(5)}$.

Transfer of dietary FA to milk has been proposed to fit a twopool model, with a fast pool representing direct transfer of absorbed FA to milk through chylomicrons and a slow pool representing indirect transfer through uptake by non-mammary tissues and cycling back to plasma in NEFA and lipoproteins (LP) ${ }^{(6)}$. Studies using ${ }^{14} \mathrm{C}$-labelled FA have determined that direct transfer to milk fat is expected to occur during the first $24 \mathrm{~h}$, whereas indirect transfer occurs 24-36 h post-absorption ${ }^{(6,7)}$.

Abomasal infusion of FA allows bypassing ruminal $\mathrm{BH}$, and therefore physiological effects of $\mathrm{BH}$ metabolites, and, more importantly, allows observation of FA absorptive and postabsorptive metabolism, as well as trafficking to milk. de Veth et $a l^{(8)}$ summarised the transfer efficiency of abomasally infused trans-10, cis-12 CLA to milk and Harvatine \& Bauman ${ }^{(9)}$ characterised the clearance of trans-10, cis-12 CLA from plasma

Abbreviations: BH, biohydrogenation; CLA, conjugated linoleic acids; FA, fatty acids; LP, lipoproteins; MFD, milk fat depression; SCD1, stearoyl-CoA desaturase.

* Corresponding author: K. J. Harvatine, fax +1 814863 6042, email kjh182@psu.edu 
and milk after cessation of abomasal infusion. However, these approaches did not allow estimation of the direct and indirect transfer rates, which may provide further understanding of inter-tissue trafficking of trans-10, cis-12 CLA and physiology of MFD. In this study, we used a perturbation tracee model, which consisted in enriching the pool of trans-10, cis-12 CLA in lactating dairy cows' plasma and milk, following observation of the time course of appearance and disappearance of the tracee (trans-10, cis-12 CLA) over a 7-d period. The main objective of this study was to characterise the kinetics of trans-10, cis-12 CLA transfer to plasma and milk and to determine the proportion transferred through the direct and indirect transfer pathways using a perturbation model. Our hypothesis was that the perturbation model would allow estimation of direct and indirect transfer rates and the construction of a mathematical compartmental model to investigate trafficking of CLA between tissues and milk.

\section{Methods \\ Experimental design and treatments}

All experimental procedures were approved by the Pennsylvania State University Institutional Animal Care and Use Committee. Five ruminally cannulated multiparous mid-lactation cows (148 (sE 86) d in milk; 44.1 (sE 11.2) kg of milk/d) were housed in tie-stalls at the Pennsylvania State University Dairy Production Research and Teaching Center. All cows were fed once daily (07.00 hours) a contemporary lactating cows' diet (16.3\% crude protein, $31.6 \%$ neutral detergent fibre, $21.5 \%$ acid detergent fibre, $24.8 \%$ starch, $3.7 \%$ diethyl ether extract) and received a single abomasal bolus infusion of an enriched CLA NEFA mixture over a $30-$ min period $2 \mathrm{~h}$ before the afternoon milking on day 0 of the experiment.

The abomasal bolus infusion consisted of $53 \mathrm{~g}$ of a NEFA mixture that provided $15.0 \mathrm{~g}$ of each CLA isomer (28.6\% trans10, cis-12 CLA; $28.6 \%$ cis-9, trans-11 CLA; Table 1). The target dose $(15 \mathrm{~g})$ causes maximal reduction in milk fat synthesis ${ }^{(10)}$, and according to previous studies was sufficient to cause a detectable increase in plasma and milk trans-10, cis-12 CLA ${ }^{(9)}$ required for a perturbation model. The NEFA mixture was prepared by saponification of a methyl ester stock (Lutalin, BASF). Briefly, the methyl ester was mixed with twice the volume of a $10 \%$ potassium hydroxide in ethanol solution in an orbital shaker at room temperature for $2 \mathrm{~h}$. The resulting NEFA were

Table 1. Fatty acid (FA) composition of the treatment mixture*

\begin{tabular}{lcc}
\hline FA & g/100 g of FA & g FA/bolus $†$ \\
\hline C16:0 & 4.46 & $2 \cdot 20$ \\
C18:0 & $2 \cdot 11$ & $1 \cdot 0$ \\
cis-9 C18: 1 & $26 \cdot 1$ & $12 \cdot 9$ \\
cis-11 C18:1 & 0.79 & 0.4 \\
C18:2n-6 & 1.86 & 0.9 \\
cis-9, trans-11 C18:2 & 30.7 & $15 \cdot 1$ \\
trans-10, cis-12 C18:2 & 30.5 & $15 \cdot 0$ \\
Unknown & 3.41 & 1.68 \\
\hline
\end{tabular}

* Mixture contained $93 \%$ FA.

$\dagger$ Calculated as $(\mathrm{g} / 100 \mathrm{~g}$ of each FA in mixture $) \times(93 \%$ FA in mixture $) \times(53 \mathrm{~g}$ of mixture in bolus) acidified to $\mathrm{pH} 4$ with $6 \mathrm{~N}$ hydrochloric acid in water and ten volumes of distilled water were added. NEFA were extracted in hexane and dried over sodium sulphate for $2 \mathrm{~h}$. Subsequently, hexane was removed in a rotary evaporator at $45^{\circ} \mathrm{C}$. Before treatments, subsamples of the CLA NEFA mixture were methylated for total fat and FA analysis as described below (dual methylation), for calculation of treatment mass (Table 1). The CLA NEFA mixture was infused manually, using a 60-ml disposable syringe, through an abomasal infusion line as described in Urrutia \& Harvatine ${ }^{(11)}$. The infusion lines were inserted approximately $9 \mathrm{~h}$ before the bolus infusion and placement in the abomasum was verified before infusion. The lines were rinsed with $50 \mathrm{ml}$ of warm water before and after CLA infusion and with $20 \mathrm{ml}$ of $70 \%$ ethanol after the final water rinse.

\section{Milk sampling and analysis}

Cows were milked twice daily at 06.30 and 18.30 hours and milk yield was determined by an integrated milk metre (AfiMilk; S.A. E. Afikim). The parlour weights were adjusted using a stall deviation calculated as described by Urrutia \& Harvatine ${ }^{(12)}$. Milk was sampled at each milking from days 0 to 7 and on days 10 and 12 relative to the bolus. A subsample of milk was stored at $4^{\circ} \mathrm{C}$ with preservative (Bronolab-WII; D\&F Control Systems, Inc.) until analysed for fat and protein by Fourier transform infrared spectroscopy (Fossomatic 4000 Milko-Scan and 400 Fossomatic; Foss Electric, Dairy One DHIA). Fat cakes were obtained from a second subsample of fresh milk by centrifugation at $1300 \boldsymbol{g}$ and then analysed for FA composition as described by Rico \& Harvatine ${ }^{(13)}$ with slight modification. Briefly, milk lipids were extracted with hexane:isopropanol, transmethylated in the presence of sodium methoxide and fatty acid methyl esters (FAME)-quantified by GC with a flame ionisation detector and a capillary column (SP-2560; $100 \mathrm{~m} \times 0.25 \mathrm{~mm}$ (i.d.) with $0 \cdot 2-\mu \mathrm{m}$ film thickness; Supelco Inc.). Initial oven temperature was $80^{\circ} \mathrm{C}$; it was increased at $2^{\circ} \mathrm{C} / \mathrm{min}$ to $190^{\circ} \mathrm{C}$ for $15 \mathrm{~min}$, and then increased at $5^{\circ} \mathrm{C} / \mathrm{min}$ to $215^{\circ} \mathrm{C}$ for $3 \mathrm{~min}$. Inlet and detector temperatures were $250^{\circ} \mathrm{C}$ with a $50: 1$ split ratio. Peaks were identified using FAME standards (GLC 68D and 780 and pure trans-10, cis-12 CLA and cis-9, trans-11 CLA; NuChek Prep Inc.; Bacterial Acid Methyl Ester Mix, 47080-U; Sigma-Aldrich Inc.; and GLC 110 mixture; Matreya LLC) and recoveries of individual FA were determined using an equal weight reference standard (GLC 461; NuChek Prep Inc.).

\section{Blood sampling and analysis}

Indwelling jugular catheters were placed the morning of the bolus infusion. Blood samples were collected in potassium EDTA tubes (Greiner Bio-One North America Inc.) at - 1, 1, 2, $4,6,12,18,24,30,36,48,72,144,216$ and $288 \mathrm{~h}$ relative to the bolus infusion. Blood was immediately placed on ice, centrifuged within $30 \mathrm{~min}$ at $1300 \mathrm{~g}$ for $15 \mathrm{~min}$ at $4^{\circ} \mathrm{C}$ and plasma was harvested and stored at $-20^{\circ} \mathrm{C}$ until laboratory analysis.

Total plasma FA profile was determined as described by Urrutia \& Harvatine ${ }^{(11)}$. Briefly, internal standards were added to plasma and lipids were extracted with hexane:isopropanol; FA were directly methylated in a dual methylation procedure 
using sodium methoxide followed by methanolic HCl. FAME were quantified as described above with a modified temperature programme (initial $70^{\circ} \mathrm{C}$, increased $8^{\circ} \mathrm{C} / \mathrm{min}$ to $110^{\circ} \mathrm{C}$, increased $4{ }^{\circ} \mathrm{C} / \mathrm{min}$ to $165^{\circ} \mathrm{C}$ for $20 \mathrm{~min}$, increased $2.5^{\circ} \mathrm{C} / \mathrm{min}$ to $215^{\circ} \mathrm{C}$ and held for $20 \mathrm{~min}$ ) and a $40: 1$ split ratio.

\section{Statistical analysis}

Experimental power was 0.80 calculated using the one-sample $Z$-test method based on observing a $0.075 \%$ increase of milk trans-10, cis-12 CLA with a SD of $0.06 \%$ using the Power \& Sample Size Calculator (Statistical Solutions, LLC). The twosided test had an $\alpha$ of 0.05 and the standard deviation was based on a similar previous experiment with an abomasal infusion of trans-10, cis-12 CLA $^{(9)}$.

Data were analysed as repeated measures using PROC MIXED in SAS (version 9.3; SAS Institute). For performance and milk FA data, the model included the random effects of cows and milking time (morning and evening) and the fixed effect of time. For plasma FA data, the model included the random effects of cows and fixed effects of time. The AR(1) covariance structure was used, time was the repeated variable and cows was the subject. Denominator df were adjusted by the Kenward-Rogers method. Data points with Studentised residuals outside of \pm 3.5 were considered outliers and excluded from analysis.

To determine direct and indirect transfer of trans-10, cis-12 CLA to milk, least square means (LSM) obtained were fit to a biexponential decay model in JMP Pro 10.0.2 (SAS Institute Inc.) by non-linear modelling procedures, and the AUC of each exponential was calculated by the following equation:

$$
\text { AUC }=-\left(\frac{\text { Intercept }}{\text { slope }}\right) \times\left(\left[\mathrm{e}^{(- \text {slope } \times t 1)}\right]-\left[\mathrm{e}^{(- \text {slope } \times t 0)}\right]\right)
$$

Total apparent transfer of CLA isomers (trans-10, cis-12 and cis-9, trans-11 CLA) to milk was calculated by subtracting the expected background mass (calculated for each post-bolus milking event, morning and evening as Pre-bolus CLA g/100g $\times$ post-bolus FA yield) from the actual mass of CLA in milk from days 1 to 7 and analysed using the fit model procedure in JMP Pro (ANOVA) with cows as random effect and CLA isomers as a fixed effect.

\section{Compartmental modelling}

Model-based compartmental analysis was applied using the Windows version of the Simulation, Analysis and Modelling software (WinSAAM version 3.3.0 ${ }^{(14)}$; http://winsaam.org). The developed compartmental models describe the kinetics of trans-10, cis-12 CLA and cis-9, trans-11 CLA, in plasma and milk, following abomasal bolus infusion. In this type of analysis, the system is represented by discrete compartments where the components under study traffic through, and processes with, similar kinetics are lumped into the same compartment ${ }^{(15)}$. In this case, the data obtained were sufficient to perform compartmental modelling of CLA kinetics and generate working hypothesis models to help inform further research.
An initial compartmental model was developed for trans-10, cis-12 CLA based on information in the literature. Then, the model structure and parameter values were iteratively adjusted to obtain a satisfactory fit of the LSM plasma and milk data to the model $^{(16)}$. Final values for model parameters (fractional transfer coefficients; $L(I, J)$, or the portion of the CLA isomer in Compartment $J$ that is transferred to Compartment $I$ each day) and their statistical uncertainties were obtained using weighted non-linear regression analysis in WinSAAM. A fractional standard deviation of $0 \cdot 1$ was used as the weighting factor for non-linear regression. Once the model for trans-10, cis-12 CLA had been developed, a similar process was applied to obtain an independent model for cis-9, trans-11 CLA. To minimise model complexity, values for kinetic parameters representing biological processes that were assumed to be similar for the two CLA isomers were made equal. Setting these parameters equal was done for simplicity and to increase the df between model parameters and data to aid in model identifiability. Additional details are provided in the Results and discussion.

The final $L(I, J) s$ were then used to calculate other kinetic parameters, including the mean transit (turnover) times $(t(J)$; the average time that a CLA molecule spends in Compartment $J$ during a single transit before exiting that compartment reversibly or irreversibly) and recycling number $(\nu(I)$; the average number of times a CLA molecule recycles to Compartment $I$ before exiting that compartment irreversibly). The mean time to milk (TTM $50 \%$ ) was calculated as the time at which $50 \%$ of the absorbed trans-10, cis-12 CLA was present in the milk pool. For more details on these kinetic parameters and their calculations, see Table 1 in Cifelli et al. ${ }^{(15)}$.

\section{Results and discussion}

The objective of this study was to characterise transfer kinetics of trans-10, cis-12 CLA. The bolus infusion contained an equal dose of cis-9, trans-11 CLA, which allowed comparison of both CLA isomers. However, characterisation of cis-9, trans-11 CLA kinetics was limited as milk cis-9, trans-11 CLA originated from three sources: ruminal synthesis from $\mathrm{BH}$ of dietary unsaturated FA, mammary gland synthesis from desaturation of trans-11 18:1 and exogenous CLA from bolus infusion. On the other hand, milk trans-10, cis-12 CLA most likely originated solely from the abomasal infusion, as trans-10, cis-12 CLA was below the level of detection in pre-trial milk and plasma samples (online Supplementary Tables S1 and S2). Cows were fed a diet high in fibre and low in starch and unsaturated FA $31.6 \%$ neutral-detergent fibre; $24.8 \%$ starch and $3.7 \%$ diethyl ether extract) to prevent synthesis of trans-10, cis-12 CLA in the rumen.

\section{Plasma and milk conjugated linoleic acids}

Plasma concentration of trans-10, cis-12 and cis-9, trans-11 CLA peaked $2 \mathrm{~h}$ post-bolus, reaching 0.29 and $0.38 \%$ of total plasma FA, respectively (Fig. 1, online Supplementary Table S1). However, both CLA isomers were enriched in plasma at the same magnitude $(0.29$ and $0.31 \%$ point increase for trans-10, 
(a)

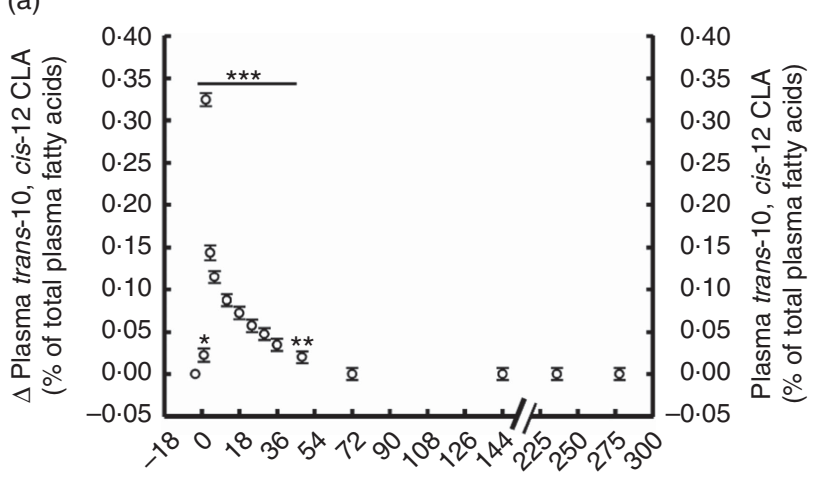

(b)

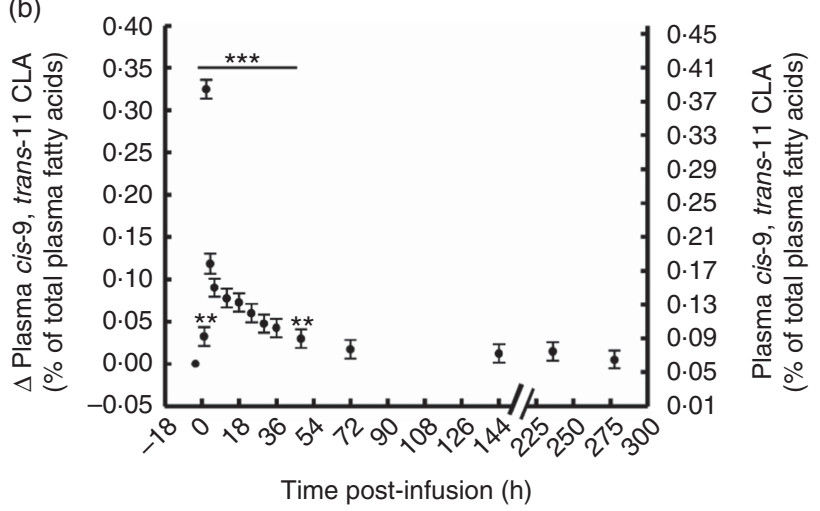

Fig. 1. Conjugated linoleic acid (CLA) isomer enrichment in plasma following abomasal infusion of $15 \mathrm{~g} / \mathrm{d}$ of trans- 10 , cis -12 and cis-9, trans -11 CLA. (a) trans-10, cis-12 CLA (\% of plasma fatty acids (FA)). (b) cis-9, trans-11 CLA ( $\%$ of plasma FA). Values are least-square means of the difference between pre- and post-bolus concentration (primary $y$-axis) and actual plasma CLA concentration (secondary $y$-axis) ( $n 5$ ), with their standard errors of the difference represented by vertical bars. Significant differences: ${ }^{\star} P<0.05$; ${ }^{\star *} P<0.01 ;{ }^{* \star *} P<0.001$

cis-12 and cis-9, trans-11 CLA, respectively) and returned to pre-bolus values by $72 \mathrm{~h}$ post-bolus $(0.03$ and $0.11 \%$ of total plasma FA for trans-10, cis-12 and cis-9, trans-11 CLA, respectively).

The temporal transfer of trans-10, cis-12 CLA to milk followed a similar pattern of plasma trans-10, cis-12 CLA, where yield and concentration peaked $14 \mathrm{~h}$ post-bolus $(0.25 \mathrm{~g} / \mathrm{h}$ and $0.49 \%$ of milk FA) and was not detectable in milk after $86 \mathrm{~h}$ (Fig. 2(a) and 3(b), online Supplementary Table S2). The temporal pattern of milk cis-9, trans-11 CLA initially followed a similar pattern, with a peak at $14 \mathrm{~h}$ post-bolus (second milking post-infusion; $0.54 \mathrm{~g} / \mathrm{h}$ and $0.98 \%$ of milk FA, online Supplementary Table S2) and returned to baseline $86 \mathrm{~h}$ post-infusion. At the initial peak, both CLA isomers were enriched in milk to a similar magnitude ( 0.48 and $0.52 \%$ point increase for trans-10, cis-12 and cis-9, trans-11 CLA, respectively). However, milk cis-9, trans-11 CLA yield and concentration presented a second rise at $86 \mathrm{~h}$ after infusion (Fig. 2(b) and 3(b)), probably because of trans-10, cis-12 CLA-driven changes in activity of the SCD1 enzyme discussed below.

Total apparent transfer of CLA isomers to milk during the 7-d period was $41 \%$ for trans- 10 , cis- 12 and $79 \%$ for cis-9, trans- 11 CLA (Table 2). Transfer of CLA isomers to milk fat has been reported to be dose dependent ${ }^{(17)}$. Individual trans-10, cis-12 (a)

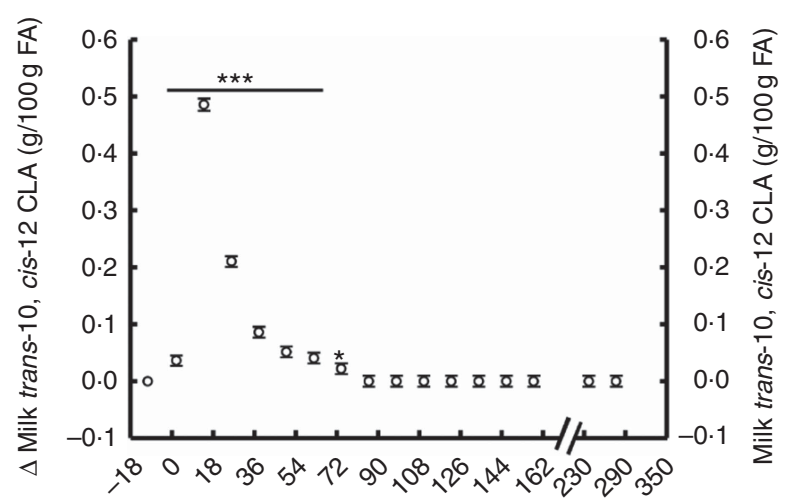

(b)

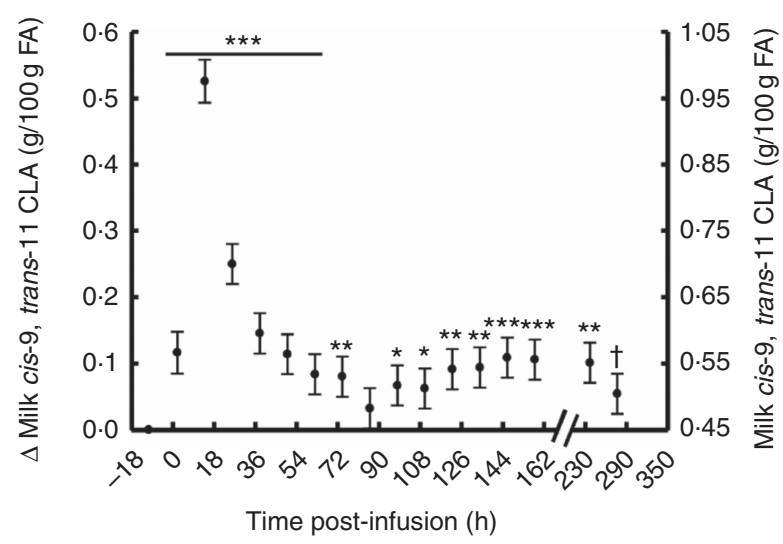

Fig. 2. Milk conjugated linoleic acid (CLA) concentration following abomasal bolus of $15 \mathrm{~g} / \mathrm{d}$ of trans- 10 , cis-12 and cis-9, trans-11 CLA. (a) Milk trans-10, cis-12 CLA (g/100 g fatty acids (FA)). (b) cis-9, trans-11 CLA (g/100 g FA). Values are least-square means of the difference between pre- and post-bolus concentrations (primary $y$-axis), and actual milk CLA concentration (secondary $y$-axis) $(n 5)$, with their standard errors of the difference represented by vertical bars. Significant differences: * $P<0.05$; ${ }^{\star *} P<0.01$; ${ }^{* \star}{ }^{*} P<0.001$; $† P<0.10$.

CLA abomasal infusion studies have reported a transfer efficiency of $15 \cdot 3-18 \cdot 8 \%^{(8,11)}$, whereas measurement of dietary trans-10, cis-12 CLA duodenal flow and transfer to milk ranged between 36 and $48 \%{ }^{(18)}$, and a meta-regression of seven experiments reported a transfer efficiency of $22 \%\left(r^{2} 0.94\right)^{(8)}$. Transfer of abomasally infused cis-9, trans-11 CLA has been previously reported to be $22.5 \%{ }^{(17)}$. In the current experiment, we observed a higher transfer of both CLA isomers to milk than previous reports, presumably because of the extended period included in the analysis $(7 \mathrm{~d} v \cdot 3-5 \mathrm{~d})$, which accounts for tissue recycling, and allows recovery of transient inhibitory effects of trans-10, cis-12 CLA on FA uptake, and milk fat synthesis and secretion. As discussed later, the remaining fractions of CLA isomers that were not transferred to milk were possibly lost during digestion as undigested FA or in post-absorptive metabolic processes including $\beta$-oxidation and incorporation into tissues.

Milk trans-10, cis-12 CLA concentration following the postbolus peak fit a non-linear biexponential decay model $\left(Y=7.39 \times \mathrm{e}^{-0.083 t}+1.32 \times \mathrm{e}^{-0.037 t} ; r^{2} 0.99, \mathrm{RMSE}=0.062\right)$. The first exponential, or fast pool, representing direct transfer from the gut to the mammary gland through chylomicrons was $73 \%$ of total trans-10, cis-12 CLA transferred to milk. The second 
exponential, or slow pool, representing indirect transfer through other tissues was the remaining $27 \%$. Indirect transfer includes all trans-10, cis-12 CLA that, before being transferred to the mammary gland, was trafficked through other tissues and cycled back to plasma through NEFA and LP. Magnitude of release and uptake of FA from other tissues is directly related to
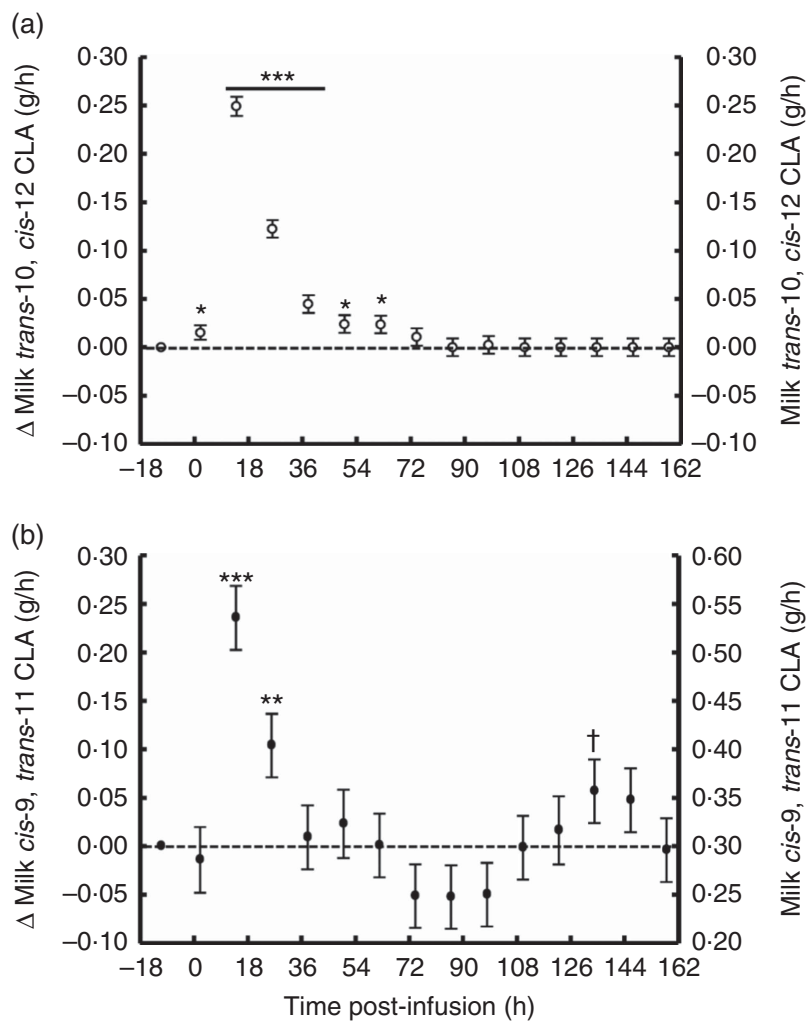

Fig. 3. Milk conjugated linoleic acid (CLA) yield following abomasal bolus of $15 \mathrm{~g} / \mathrm{d}$ of trans- 10 , cis-12 and cis-9, trans-11 CLA. (a) Milk trans-10, cis-12 CLA $(\mathrm{g} / \mathrm{h})$. (b) cis-9, trans-11 CLA ( $\mathrm{g} / \mathrm{milking}$ ). Values are least-square means of the difference between pre- and post-bolus yield (primary $y$-axis) and actual milk CLA yield (secondary $y$-axis) ( $n 5$ ), with their standard errors of the difference represented by vertical bars. Significant differences: ${ }^{*} P<0.05 ;{ }^{*}{ }^{*} P<0.01$; *** $P<0.001 ;+P<0.10$. energy balance and lactation stage ${ }^{(19,20)}$, with greater tissue uptake expected in a positive energy balance status. In our study, calculated energy balance was positive for all cows (9.8 (sE 2.9) Mcal/d); however, as discussed later, compartmental modelling suggests that it is unlikely that a major fraction of trans-10, cis-12 CLA was incorporated into tissues other than the mammary gland.

Direct transfer was completed by $37 \mathrm{~h}$ after bolus infusion, based on intersection of the exponentials. Palmquist \& Mattos ${ }^{(6)}$ used this bi-exponential model approach to investigate transfer of ${ }^{14} \mathrm{C}$-labelled LA to milk. In their experiments, total LA transfer to milk ranged between 39 and $56 \%$ depending on the basal diet. Of the total LA transferred, direct transfer ranged from 86 to $90 \%$ and indirect transfer ranged from 10 to $14 \%$. Our data show lower direct transfer of trans-10, cis-12 CLA, presumably owing to differences in CLA post-absorptive metabolism and to acute inhibition of FA transfer and secretion in milk owing to the milk fat depressing action of this CLA isomer.

Milk cis-9, trans-11 CLA following the bolus in the current experiment did not fit the non-linear model because of the second peak in milk cis-9, trans-11 CLA that occurred after $86 \mathrm{~h}$.

\section{Milk fat, fatty acids and desaturase ratios}

MFD is characterised by a reduction in milk fat yield up to $50 \%$, without reduction of milk yield or other milk components. During MFD, yield of both de novo-synthesised and preformed FA are decreased in milk, but there is a greater reduction in de novo-synthesised $\mathrm{FA}^{(5)}$. In this study, milk fat concentration and yield progressively decreased following CLA bolus infusion, reaching a nadir $4 \mathrm{~d}$ post-infusion and returning to pre-bolus values by days 5 and 6, respectively (online Supplementary Fig. S1). Concentration of milk de novo-synthesised FA (sum of all saturated and unsaturated paired number FA less than 16 carbons in length; <16 C) and mixed-source FA (sum of all saturated and unsaturated 16 carbon FA; 16 C FA) were acutely reduced following the CLA bolus, reached a nadir at $50 \mathrm{~h}$ after infusion with an 8.5 and $9.5 \%$ reduction and slowly

Table 2. Transfer of conjugated linoleic acid (CLA) isomers to milk fat following abomasal bolus (Mean values with their standard errors)

\begin{tabular}{l}
\hline \multicolumn{1}{c}{ CLA isomer* } \\
\cline { 2 - 5 } \\
\cline { 2 - 5 }
\end{tabular}


returned to pre-bolus values by 288 and $110 \mathrm{~h}$ after infusion, respectively (online Supplementary Fig. S2). As expected, the proportion of milk preformed FA (sum of all known saturated and unsaturated FA not taken into account into de novo or mixed-source FA and all >16 C FA) progressively increased, peaked at $50 \mathrm{~h}$ (13\% increase) and remained high throughout the study. The time course of milk fat concentration and yield, and milk de novo and preformed FA concentration, followed a similar pattern to that observed by Harvatine \& Bauman ${ }^{(9)}$ who provided trans-10, cis-12 CLA as a $7 \cdot 5$-g bolus followed by $2.5 \mathrm{~g}$ every $4 \mathrm{~h}$. Inhibition of de novo and mixed-source FA synthesis is expected with trans-10, cis-12 CLA infusion, owing to transcriptional regulation of genes involved in milk fat synthesis by this CLA isomer ${ }^{(5)}$.

Expression of important lipogenic enzymes including SCD1 (i.e. FA synthase and acetyl-CoA carboxylase $\alpha$ ) and lipogenic transcription factors (sterol regulatory element binding protein 1 and thyroid hormone responsive spot 14) are coordinately reduced in the lactating mammary gland during abomasal trans-10, cis-12 CLA infusion ${ }^{(21,22)}$. Particularly, SCD1 expression was reduced $54 \%(P<0 \cdot 01)$ in mammary tissue during abomasal infusion of $13.6 \mathrm{~g} / \mathrm{d}$ of trans-10, cis-12 CLA ${ }^{(22)}$. Desaturase ratios are the product:precursor ratios for the SCD1 enzyme (ex. C14 ratio $=\mathrm{C} 14: 1 /(\mathrm{C} 14: 0+\mathrm{C} 14: 1))$, and despite the lack of correlation with SCD1 enzyme activity in adipose tissue $^{(23)}$ milk desaturase ratios are often used as a proxy for mammary gland SCD1 enzyme activity in MFD experimental models (trans-10, cis-12 CLA abomasal infusion) ${ }^{(9,22)}$. The SCD1 enzyme activity and the desaturase ratios are acutely reduced by trans-10, cis-12 CLA, with Harvatine \& Bauman ${ }^{(9)}$ reporting nadir at $12 \mathrm{~h}$ after initiation of infusion. In the present study, milk C14 desaturase ratio followed an inverse pattern of milk trans-10, cis-12 CLA, dropping $15 \%$ at $14 \mathrm{~h}$ post-infusion and progressively returning to pre-bolus values $50 \mathrm{~h}$ postinfusion (online Supplementary Fig. S3). The C16 and C18 desaturase ratios were also decreased 9.5 and $13 \%$ and returned to baseline at 26 and $38 \mathrm{~h}$, respectively (online Supplementary Fig. S3). As expected, the reduction and recovery of SCD1 activity was opposite of the pattern of milk trans-10, cis-12 CLA, which indeed illustrates the inhibitory effect of this CLA isomer on the SCD1 enzyme. As discussed by Harvatine \& Bauman $^{(9)}$, the short-life of SCD1 enzyme (2-4h) allows observation of acute responses in gene expression resulting either from direct trans-10, cis-12 CLA inhibition or through other signalling pathways regulating milk fat synthesis enzyme expression and activity.

Inhibition of the SCD1 gene has important implications for determining endogenous synthesis and transfer of cis-9, trans-11 CLA to milk fat. Although we expect that endogenous synthesis of cis-9, trans-11 CLA was decreased in a similar pattern as $14 \mathrm{C}$ desaturase ratio, transfer of exogenous cis-9, trans-11 CLA provided in the bolus to milk limits the interpretation of changes in the trans-11 18:1 desaturase ratio.

Interestingly, $126 \mathrm{~h}$ post-bolus infusion, the $14 \mathrm{C}$ desaturase ratio increased above pre-bolus levels. This may represent an overshoot in regulation of SCD1 as the trans-10, cis-12 CLA inhibition was relieved. The second peak in cis-9, trans-11 CLA appears to be driven by this increase in SCD1 activity.

\section{Compartmental modelling}

The major objective of this study was to quantify trans-10, cis-12 CLA transfer to milk through the direct and indirect pathway, and, through compartmental modelling, to characterise tissue compartments involved in trans-10, cis-12 CLA transfer to milk. For this, compartmental models (one for each CLA isomer) were independently developed to describe the observed data (CLA in plasma and milk) and parameter values were determined using WinSAAM. In the trans-10, cis-12 CLA model (Fig. 4(a)), Compartment 2 represents the abomasum, which is the site of bolus infusion, as well as the site of loss of undigested trans-10, cis-12 CLA. Absorbed trans-10, cis-12 CLA is transferred to delay component 3, representing the site of chylomicron production. Chylomicron trans-10, cis-12 CLA (mainly in TAG) is secreted into a fast turning-over plasma pool (Compartment 4) that can either be transferred to a slow turning-over non-chylomicron LP pool (Compartment 5; with CLA presumably in phospholipids or cholesteryl esters) or to an accessible pool in the mammary gland (Compartment 6). Observed data for plasma trans-10, cis-12 CLA were partitioned into two simulated compartments (Compartments 4 and 5) using a 'summer function' in WinSAAM to fit the data to a model that reflects known physiology. Uptake of plasma CLA by extravascular tissues is represented in Compartment 6. During the model development process, a separate compartment for extravascular tissues other than the mammary gland was included; however, based on best fit, extravascular tissues were grouped into one. We report that this extravascular compartment is primarily composed by the mammary tissue with the assumption that the mammary gland is the principal tissue involved in FA uptake, based on the known high rate of FA uptake in the lactating mammary gland ${ }^{(6)}$. The data also indicate that, once in the extravascular tissue compartment, trans-10, cis-12 CLA can be either secreted to luminal milk fat (Compartment 8) and delivered to milk (Compartments 9 (twice-daily collected milk) and 10 (cumulative milk)) or transferred to a pool of CLA that is transiently unavailable (Compartment 7) and slowly recycles to the available pool for milk fat synthesis. In addition, the data indicate that there is irreversible loss of trans-10, cis-12 CLA from the unavailable extravascular tissue pool $[\mathrm{L}(0,7)]$ that might be explained by $\beta$-oxidation; however, mammary oxidation of FA is generally low ${ }^{(24,25)}$. At present, the cellular location of the unavailable trans-10, cis-12 CLA pool (Compartment 7) and the biological fate of the irreversible loss are biologically unknown.

Once the model for trans-10, cis-12 CLA was completed, an independent model for cis-9, trans-11 CLA was developed (Fig. 4(b)), and then parameter values were made the same $(--\rightarrow)$ in the cis-9, trans-11 CLA model as in the model for trans-10, cis-12 CLA for biological processes assumed to be the same for the two isomers (i.e. absorption, plasma LP transport until CLA is taken up by extravascular tissue, transfer of CLA to intraluminal milk fat). In addition, because trans-11 18:1 is a precursor for cis-9, trans-11 CLA, data for plasma trans-11 18:1 (component 35) were used as a forcing function to help define the system kinetics for cis-9, trans-11 CLA. As shown in Fig. 4(b), plasma trans-11 18:1 turned over into plasma or extravascular, primarily mammary tissue cis-9, trans-11 CLA (Compartment 16), or it was directly transferred to a trans-11 18:1 milk pool 
(a)

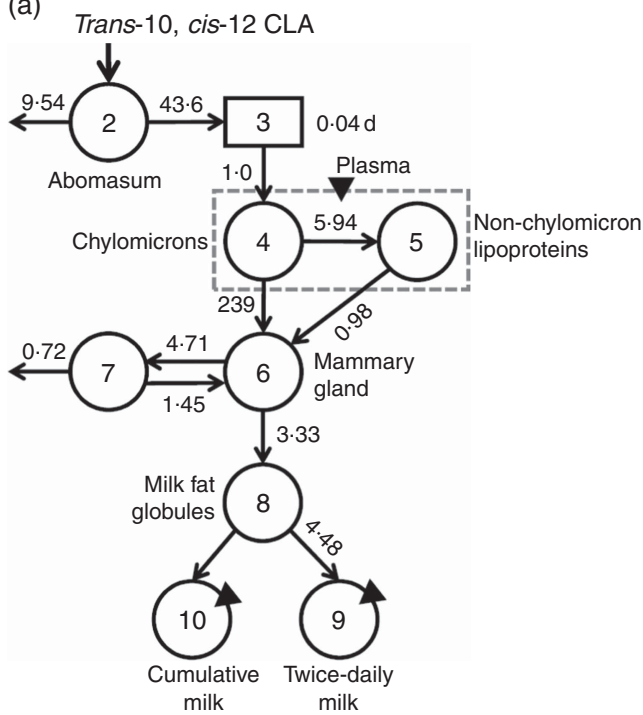

(b)

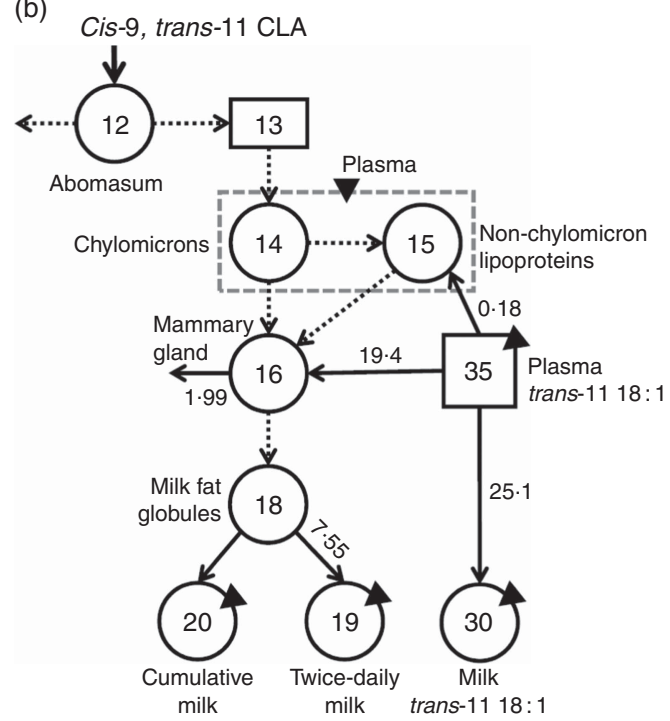

Fig. 4. Proposed compartmental models for conjugated linoleic acid (CLA) isomer kinetics in lactating dairy cows. (a) Model for trans-10, cis-12 CLA and (b) shows the partially parallel model for cis-9, trans-11 CLA. $\boldsymbol{\nabla}$ and $\mathbf{\Delta}$, sites of sampling; $\bigcirc$, compartments; $\square$, delay elements; $\square$, a forcing function; $\longrightarrow$ and - - - $\rightarrow$, fractional transfer coefficients $[L(I, J) s]$ or the fraction of CLA in Compartment $J$ that is transferred to Compartment / each day. Model-predicted values for $L(I, \mathcal{S}) s$ are shown with the appropriate arrows. (a) Compartment 2 represents the site of administration of the bolus dose (abomasum). Component 3 represents CLA absorption and packaging into chylomicrons. Compartments 4 and 5 represent CLA in chylomicrons and non-chylomicron lipoproteins, respectively; total plasma CLA is the sum of these two compartments. Compartment 6 represents a CLA pool in extravascular primarily mammary tissue, which is available for milk fat synthesis and secretion into the lumen of mammary ducts (Compartment 8); CLA in Compartment 6 can also exchange with a second, non-accessible extravascular primarily mammary tissue pool of CLA (Compartment 7, from which there is irreversible loss). Compartment 9 represents secreted milk collected twice daily and Compartment 10 represents cumulative milk collections. The fractional transfer rate for CLA to the two milk compartments is identical $[L(10,8)=L(9,8)]$, except that Compartment 9 was 'emptied' after each milk collection. (b) Compartments 35 and 30 represent plasma and milk trans-11 18:1, respectively, resulting from absorption and mammary gland uptake of this fatty acid. The remaining parts of the model are the same as in (a) with $L(3,2)=L(13,12), L(4,3)=L(14,13), L(5,4)=L(15,14), L(6,4)=L(16,14), L(6,5)=L(16,15)$ and $L(8,6)=L(18,16)$.

(Compartment 30). In contrast to the model for trans-10, cis-12 CLA, only one extravascular pool was required to fit the data for cis-9, trans-11 CLA (Compartment 16, from which there was irreversible loss). The absence of an unavailable extravascular pool of cis-9, trans-11 CLA suggests that the two CLA isomers are processed differently and therefore compartmental modelling provides support for the hypothesis that cis-9, trans-11 and trans-10, cis-12 CLA are biologically unique.

Observed and model-predicted fits to the data for both CLA isomers in plasma and milk $v$. time are shown in Fig. 5. For trans10, cis-12 CLA in plasma (Fig. 5(a)), the composite modelsimulated curve (-) represents the sum of the fast turning-over chylomicron pool (...........; Compartment 4, shown in Fig. 4(a)) and the slow turning-over non-chylomicron LP pool $(\cdots \cdots$; Compartment 5). Chylomicron trans-10, cis-12 CLA peaked at approximately1 $\mathrm{h}$ (Fig. 5(a) inset) and then rapidly fell as CLA was either transferred to other LP or taken up by the mammary gland. Trans-10, cis-12 CLA in non-chylomicron LP gradually increased with time and by approximately $2 \mathrm{~h}$ was higher than CLA in chylomicrons. Fig. 5(b) shows the model-simulated fit to the data for twice-daily milk collections (.....; Compartment 9) and cumulative milk (—; Compartment 10). For the individual milk collections, trans-10, cis-12 CLA decreased from approximately $14 \mathrm{~h}$ to $3.5 \mathrm{~g} \mathrm{~d}$, after which this isomer was no longer detectable in milk. Over the same time, trans-10, cis-12 CLA in cumulative milk increased, reaching a plateau when the isomer reached approximately $6 \mathrm{~g}$ in milk.

The model-predicted kinetic parameters $(L(I))$,$s and the delay$ time in component 3) are indicated in Fig. 4 with arrows describing traffic between compartments. Using these parameter values, the model estimated that $18 \%$ of the trans-10, cis-12 CLA that entered the system was irreversibly lost from Compartment 2 (abomasum) during digestive processes, likely owing to non-absorbed CLA. For simplification, our proposed model did not include a compartment representing duodenum; therefore, non-absorbed CLA is represented as abomasal loss. Previous studies have shown high apparent intestinal digestibility of trans-10, cis-12 CLA, ranging from 69 to $100 \%$, depending on basal diet composition ${ }^{(18,26,27)}$. In addition, of the trans-10, cis-12 CLA that was absorbed (82\%), $71 \%$ was transferred to milk (Compartment 10), whereas $29 \%$ was irreversibly lost from Compartment 7 , presumably by oxidation. Experimental approaches to measure transfer of trans-10, cis-12 CLA to body tissues have not allowed an accurate approximation ${ }^{(28)}$, and in the present study tissues other than plasma and milk were not sampled. However, based on the transfer of trans-10, cis-12 CLA to milk (58\% from compartmental modelling $(82 \times 71 \%)$ and $41 \%$ from direct measurement (Table 2$))$ and the irreversible loss $(23.8 \%$ from compartmental modelling $(82 \times 29 \%))$ it is unlikely that a major fraction of trans-10, cis-12 CLA was incorporated into extravascular tissues other than the mammary gland. Before being irreversibly lost from the unavailable extravascular pool, trans-10, cis-12 CLA recycled between the two extravascular compartments an average of 1.4 times. The model also predicted that the TTM $50 \%$ for trans-10, cis-12 CLA was $13 \mathrm{~h}$. Mean transit times for CLA isomers in the plasma pools, mammary pools and the pool representing intraluminal milk fat are shown in Table 3. 

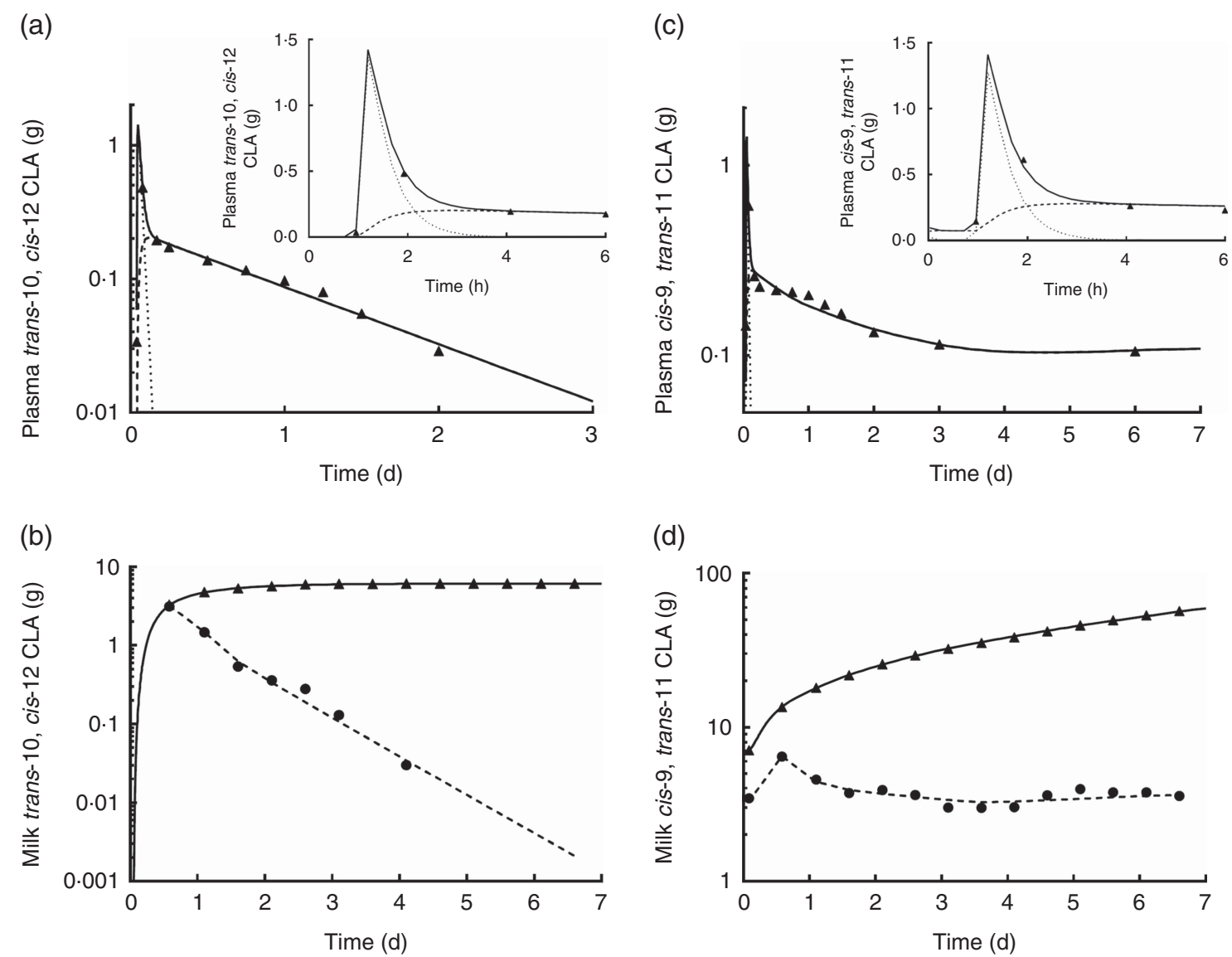

Fig. 5. Observed data and model predicted fit for plasma and milk trans-10, cis-12 and cis-9, trans-11 conjugated linoleic acid (CLA) v. time. (a) and (c) show observed data $(\boldsymbol{\Lambda})$ and model-predicted curves for plasma $(-)$, as well as for the two simulated plasma pools (chylomicrons (.............) and non-chylomicron lipoproteins $(\ldots \ldots))$; insets show curves from 0 to $6 \mathrm{~h}$. (b) and (d) show observed data $(\boldsymbol{\Lambda}$ and $\mathbf{O})$ and model-calculated curves for twice-daily milk collections $(\cdots \ldots)$ and for cumulative milk collections (-). The models are shown in Fig. 4.

Table 3. Model-derived mean transit times for conjugated linoleic acid $(C L A)$ isomers in lactating dairy cows

\begin{tabular}{|c|c|c|}
\hline \multirow[b]{2}{*}{ Mean transit time $(t(J)) \dagger \ddagger(h)$} & \multicolumn{2}{|c|}{ CLA isomer* } \\
\hline & $\begin{array}{l}\text { trans-10, } \\
\text { cis-12 }\end{array}$ & $\begin{array}{c}\text { cis- } 9 \\
\text { trans- } 11\end{array}$ \\
\hline Plasma chylomicrons & 0.245 & 0.245 \\
\hline Plasma non-chylomicrons lipoproteins & $61 \cdot 1$ & $61 \cdot 1$ \\
\hline $\begin{array}{l}\text { Extravascular primarily mammary tissue } \\
\text { (available) }\end{array}$ & 7.46 & $11 \cdot 3$ \\
\hline $\begin{array}{l}\text { Extravascular primarily mammary tissue } \\
\text { (unavailable) }\end{array}$ & $27 \cdot 6$ & \\
\hline Intraluminal milk fat & 13.4 & 7.95 \\
\hline \multicolumn{3}{|c|}{$\begin{array}{l}\text { * Treatment was a single abomasal bolus of } 15 \mathrm{~g} \text { of each CLA isomer, trans }-10 \text {, cis-12 } \\
\text { CLA and cis-9, trans-11 CLA, infused over a } 30 \text {-min period. Values were obtained } \\
\text { by compartmental modelling of least-square means for each CLA isomer, } n 5 \text {. The } \\
\text { model is shown in Fig. } 4 \text {. } \\
\dagger \text { Calculated as } t(J)=1 / \sum L(I, \zeta s \text { exiting Compartment } J \text {. }\end{array}$} \\
\hline
\end{tabular}

For plasma cis-9, trans-11 CLA, Fig. 5(c) shows the modelpredicted composite plasma curve (-) and simulations for cis-9, trans-11 CLA in the two plasma pools: the fast (............) and slow (......) turning-over compartments (Compartments 14 and 15, respectively, as shown in Fig. 4(b)). As shown in Fig. 5(c) inset (0 to $6 \mathrm{~h}$ ), and similar to trans-10, cis-12 CLA (Fig. 5(a)), cis-9, trans-11 CLA in chylomicrons peaked at approximately $1 \mathrm{~h}$, the same time that cis-9, trans-11 CLA began to gradually increase in non-chylomicron LP. The two curves crossed at approximately $2 \mathrm{~h}$, after which cis-9, trans-11 CLA was higher in non-chylomicron LP. Fig. 5(d) shows the model-predicted fit for the twice-daily milk collections (......; Compartment 19) and cumulative milk (— milk collections indicate that cis-9, trans-11 CLA increased slightly before $1 \mathrm{~d}$ and then, in contrast to trans-10, cis-12 CLA (Fig. 5(b)), was present in milk at a relatively steady level (3-4 g) until the end of the experiment. As a result, cumulative milk collections for cis-9, trans-11 CLA increased linearly from approximately $14 \mathrm{~h}$, and by 7 th day they were ten times the amount of trans-10, cis-12 CLA found in milk.

On the basis of results from the compartmental models, cis-9, trans-11 CLA in the mammary gland was transferred to milk at a higher fractional rate than trans-10, cis-12 CLA (7.55 v. 4.48/d), which is in agreement with our direct measurements (Table 2) that showed higher transfer to milk of cis-9, trans-11 than trans-10, cis-12 CLA (79v. 41\%). In addition, cis-9, trans-11 CLA appeared to be lost (presumably oxidised) from the extravascular tissue pool (Compartment 16) at a higher fractional rate compared with trans-10, cis-12 CLA. This finding could relate to trans-10, cis-12 
CLA recycling in the extravascular primarily mammary tissue that was not found to occur for cis-9, trans-11 CLA. On the basis of these models, we also estimated that approximately $40 \%$ of plasma trans-11 18:1 was converted to cis-9, trans-11 CLA in the mammary gland for further transfer to milk fat, that $<1 \%$ was converted to cis-9, trans-11 CLA before mammary gland uptake and that the remaining fraction was directly transferred to milk as trans-11 18:1.

\section{Conclusions}

This study characterised the transfer of trans-10, cis-12 and cis-9, trans-11 CLA to plasma and milk using a perturbation experimental model, and showed higher milk transfer rates for trans-10, cis-12 CLA than previous reports, owing to extended sample collection period, which allowed measurement of indirect transfer. Compartmental modelling of CLA isomers revealed an interesting working hypothesis of trafficking of trans-10, cis-12 CLA within extravascular tissues primarily represented by the mammary gland, with a transient pool of unavailable trans-10, cis-12 CLA that is slowly transferred to milk. However, this work could be extended to test the interaction of lactation and diet effects. Overall, this study provides a better understanding of the physiology of MFD and, importantly, of tissue barriers (mechanisms) involved in the delay of MFD recovery.

\section{Acknowledgements}

The authors thank Y. Ying, F. Pino, R. Bomberger and N. Shulman (Penn State University, University Park) for their assistance during experimental periods and laboratory analyses, as well as Dr Arnulf Troescher (BASF) for helpful discussion and BASF for donating the CLA stock.

This research was funded by Penn State University. N. L. U. was a recipient of a PhD scholarship from the Foreign Fulbright Program, USA, and from CONICYT, Chile. M. T. was a recipient of an internship from the Summer Research Opportunity Program of Penn State University, USA.

N. L. U. and K. J. H. designed the experiments; N. L. U. and M. B. conducted the experiment; N. L. U., M. T., J. L. F., M. H. G. and K. J. H. analysed experimental samples and data; and N. L. U., J. L. F. and K. J. H. wrote the paper and K. J. H. has primary responsibility for the final content.

The authors declare that there are no conflicts of interest.

\section{Supplementary material}

For supplementary material/s referred to in this article, please visit https://doi.org/10.1017/S0007114518001551

\section{References}

1. Park Y \& Pariza MW (2007) Mechanisms of body fat modulation by conjugated linoleic acid (CLA). Food Res Int $\mathbf{4 0}$, 311-323.

2. Shingfield KJ \& Wallace RJ (2014) Chapter 1: synthesis of conjugated linoleic acid in ruminants and humans. In Conjugated Linoleic Acids and Conjugated Vegetable Oils, pp. 1-65 [B Sels and A Philippaerts, editors]. Cambridge: The Royal Society of Chemistry.

3. Griinari JM, Corl BA, Lacy SH, et al. (2000) Conjugated linoleic acid is synthesized endogenously in lactating dairy cows by delta(9)-desaturase. J Nutr 130, 2285-2291.

4. Bauman DE \& Griinari JM (2001) Regulation and nutritional manipulation of milk fat: low-fat milk syndrome. Livest Prod Sci 70, 15-29.

5. Harvatine KJ, Boisclair YR \& Bauman DE (2009) Recent advances in the regulation of milk fat synthesis. Animal 3, 40-54.

6. Palmquist D \& Mattos W (1978) Turnover of lipoproteins and transfer to milk fat of dietary (1-carbon-14) linoleic acid in lactating cows. J Dairy Sci 61, 561-565.

7. Palmquist DL \& Conrad HR (1971) Origin of plasma fatty acids in lactating cows fed high grain or high fat diets. J Dairy Sci 54, 1025-1033.

8. de Veth MJ, Griinari JM, Pfeiffer A-M, et al. (2004) Effect of CLA on milk fat synthesis in dairy cows: comparison of inhibition by methyl esters and free fatty acids, and relationships among studies. Lipids 39, 365-372.

9. Harvatine KJ \& Bauman DE (2011) Characterization of the acute lactational response to trans-10, cis-12 conjugated linoleic acid. J Dairy Sci 94, 6047-6056.

10. Baumgard LH, Sangster JK \& Bauman DE (2001) Milk fat synthesis in dairy cows is progressively reduced by increasing supplemental amounts of trans-10, cis-12 conjugated linoleic acid (CLA). J Nutr 131, 1764-1769.

11. Urrutia N \& Harvatine KJ (2017) Effect of conjugated linoleic acid and acetate on milk fat synthesis and adipose lipogenesis in lactating dairy cows. J Dairy Sci 100, 5792-5804.

12. Urrutia NL \& Harvatine KJ (2017) Acetate dose-dependently stimulates milk fat synthesis in lactating dairy cows. I Nutr 147, 763-769.

13. Rico DE \& Harvatine KJ (2013) Induction of and recovery from milk fat depression occurs progressively in dairy cows switched between diets that differ in fiber and oil concentration. J Dairy Sci 96, 6621-6630.

14. Wastney ME, Patterson BH, Linares OA, et al. (1999) 6:WinSAAM. In Investigating Biological Systems Using Modeling, pp. 95-138. New York: Academic Press.

15. Cifelli CJ, Green JB \& Green MH (2007) Use of model-based compartmental analysis to study vitamin A kinetics and metabolism. Vitam Horm 75, 161-195.

16. Stefanovski D, Moate PJ \& Boston RC (2003) WinSAAM: a windows-based compartmental modeling system. Metabolism 52, 1153-1166.

17. Chouinard PY, Corneau L, Barbano DM, et al. (1999) Conjugated linoleic acids alter milk fatty acid composition and inhibit milk fat secretion in dairy cows. J Nutr 129, 1579-1584.

18. Pappritz J, Lebzien P, Meyer U, et al. (2011) Duodenal availability of conjugated linoleic acids after supplementation to dairy cow diets. Eur J Lipid Sci Technol 113, 1443-1455.

19. McNamara JP \& Hillers JK (1986) Regulation of bovine adipose tissue metabolism during lactation. 1: Lipid synthesis in response to increased milk production and decreased energy intake. J Dairy Sci 69, 3032-3041.

20. Bauman DE \& Currie WB (1980) Partitioning of nutrients during pregnancy and lactation: a review of mechanisms involving homeostasis and homeorhesis. J Dairy Sci 63 , $1514-1529$.

21. Harvatine KJ \& Bauman DE (2006) SREBP1 and thyroid hormone responsive spot 14 (S14) are involved in the regulation of bovine mammary lipid synthesis during diet-induced milk fat depression and treatment with CLA. J Nutr 136, 2468-2474. 
22. Baumgard LH, Matitashvili E, Corl BA, et al. (2002) Trans-10, cis-12 conjugated linoleic acid decreases lipogenic rates and expression of genes involved in milk lipid synthesis in dairy cows. J Dairy Sci 85, 2155-2163.

23. Archibeque SL, Lunt DK, Gilbert CD, et al. (2005) Fatty acid indices of stearoyl-CoA desaturase do not reflect actual stearoyl-CoA desaturase enzyme activities in adipose tissues of beef steers finished with corn-, flaxseed-, or sorghumbased diets. J Anim Sci 83, 1153-1166.

24. Emery RS (1973) Biosynthesis of milk fat. J Dairy Sci 56, $1187-1195$.

25. Annison EF, Linzell JL, Fazakerley S, et al. (1967) The oxidation and utilization of palmitate, stearate, oleate and acetate by the mammary gland of the fed goat in relation to their overall metabolism, and the role of plasma phospholipids and neutral lipids in milk-fat synthesis. Biochem $J \mathbf{1 0 2}$ 637-647.

26. Loor JJ, Ueda K, Ferlay A, et al. (2004) Biohydrogenation, duodenal flow, and intestinal digestibility of trans fatty acids and conjugated linoleic acids in response to dietary forage: concentrate ratio and linseed oil in dairy cows. J Dairy Sci $\mathbf{8 7}$, $2472-2485$.

27. Loor JJ, Ueda K, Ferlay A, et al. (2005) Intestinal flow and digestibility of trans fatty acids and conjugated linoleic acids (CLA) in dairy cows fed a high-concentrate diet supplemented with fish oil, linseed oil, or sunflower oil. Anim Feed Sci Technol 119, 203-225.

28. von Soosten D, Kramer R, Jahreis G, et al. (2013) Transfer of conjugated linoleic acids into different tissues of dairy cows. Arch Anim Nutr 67, 119-133. 